\title{
Aloperine inhibits the progression of non-small-cell lung cancer through the PI3K/ Akt signaling pathway
}

\author{
Fujuan Liu' ${ }^{1}$ Tao Liu ${ }^{2}$ and Haiying Li ${ }^{3^{*}}$ (i)
}

\begin{abstract}
Background: Lung cancer has become the leading cause of cancer-related death worldwide and non-small-cell lung cancer (NSCLC) accounts for approximately 85\% of cases. Aloperine (ALO), an alkaloid active natural component from S. alopecuroide, has been found to exhibit anti-inflammatory, anti-tumor and anti-viral activity. However, Whether ALO exerts anti-tumor function on NSCLC remains poorly understood, and the underlying mechanisms remain unknown.

Methods: The CCK-8, colony formation, cell apoptosis with flow cytometry, wound healing and transwell cell invasion assays, were used to analyze the tumor progression of $\mathrm{H} 1299$ and A549 cells treated with ALO in vitro, and the xenograft model was constructed to assess the effect of ALO in vivo. The expression of protein was detected by Western blotting.
\end{abstract}

Results: ALO suppressed the cell proliferation, self-renewal, migration and invasion, induced apoptosis in A549 and H1299 cell. Furthermore, ALO significantly enhanced the level of cytochrome c in cytosol, and resulted in the dramatical increased levels of the cleaved caspase-3, caspased-9 and PARP. ALO also inhibited the expression of MMP-2 and MMP-9. Additionally, ALO also reduced p-AKT and p-mTOR to attenuate the PI3K/AKT signaling pathway.

Conclusion: This study unveils a rationale for ALO through PI3K/Akt signaling pathway affecting the cell progression such as cell growth, apoptosis and invasion, and ALO acts as a potential chemotherapeutic agent for NSCLC.

Keywords: Aloperine, NSCLC, PI3K/Akt pathway, Tumor progression

\section{Introduction}

Lung cancer (LC) is the most common cause of cancer death worldwide [1]. Non-small-cell lung cancer (NSCLC) is the most histological subtypes of LC, accounting for $85 \%$ of the total number of LC [2]. Currently, surgery, radiotherapy and chemotherapy are the main therapies for lung cancer. However, the treatment effects are not effective and have adverse effects. Thus, it is necessary to develop novel treatment strategies that

\footnotetext{
*Correspondence: lihaiying@qiluhospital.com

${ }^{3}$ Department of Ultrasound, Qilu Hospital of Shandong University, No. 107, Wenhuaxi Rd., Jinan 250012, Shandong, China

Full list of author information is available at the end of the article
}

effectively treat NSCLC. Natural products can exhibit many beneficial effects on human health and have lower side effects in treatment cancers [3], there is growing concern about plant-derived drugs as an alternative to cancer therapy. Identifying of new compounds among natural sources with chemotherapeutic properties is urgent.

Aloperine (ALO) is a quinolizidine alkaloid drug that is extracted from S. alopecuroides, which is a traditional Chinese medicine [4]. ALO has been shown to exhibit anti-inflammatory, anti-allergenic and antiviral activity [5-8]. More importantly, emerging evidences indicates that ALO exerts anti-tumor functions on multi-tumors such as hepatocellular carcinoma [9], osteosarcoma [10], original author(s) and the source, provide a link to the Creative Commons licence, and indicate if changes were made. The images or other third party material in this article are included in the article's Creative Commons licence, unless indicated otherwise in a credit line to the material. If material is not included in the article's Creative Commons licence and your intended use is not permitted by statutory regulation or exceeds the permitted use, you will need to obtain permission directly from the copyright holder. To view a copy of this licence, visit http://creativecommons.org/licenses/by/4.0/. The Creative Commons Public Domain Dedication waiver (http://creativeco mmons.org/publicdomain/zero/1.0/) applies to the data made available in this article, unless otherwise stated in a credit line to the data. 
colon cancer [11], breast cancer [12]. However, whether ALO exerts anti-tumor activities on NSCLC is unknown, and the underlying mechanisms have not been defined.

Apoptosis is a programmed form of cell death and represents the major mechanism of cell death in cancer therapies [13, 14]. Apoptosis can be triggered through either extrinsic or intrinsic pathways. Both pathways converge to activate the effector apoptotic caspases (i.e. caspases-3, -6 and -7 ) resulting in apoptotic cell death [15]. The intrinsic pathway is primarily regulated by the $\mathrm{Bcl}-2$ family. $\mathrm{Bcl}-2$ and $\mathrm{Bax}$ are the two main proteins that play a key role of pro-survival and pro-apoptotic functions, respectively. Upon activated, Bax forms multispanning monomers that oligomerize to permeabilize mitochondrial membranes, leading to the proteins normally retained in the intermembrane space spread into the cytosol16. Additionally, Matrix metalloproteinases (MMP) including MMP-2 and MMP-9 play a major role in tumor invasion by degrading the extracellular matrix [17]. It has been reported that MMP-2 and MMP-9 are essential in in NSCLC invasion and metastasis $[18,19]$.

It is well known that the phosphatidylinosito-3-kinase/ protein kinase B (PI3K/Akt) signaling pathway plays vital role in the growth and survival of cancer cells [20,21]. Notably, abnormal Akt activation is a poor prognostic factor for all stages of NSCLC [22]. Moreover, activated AKT protects NSCLC cells from chemotherapy and radiation-induced apoptosis [23, 24]. Thus, inhibition of the PI3K/Akt signaling pathway is an attractive therapeutic strategy in NSCLC.

Here, we found that ALO suppressed cell proliferation and induced apoptosis in via promoting intrinsic apoptotic pathway in both A549 and H1299 NSCLC cells. Besides, ALO inhibited the invasion in A549 and H1299 cells through downregulated MMP-2 and MMP-9 expression. More importantly, ALO attenuated PI3K/Akt signaling pathway, which is involved in tumor cell proliferation, metastasis and apoptosis.

\section{Materials and methods \\ Cell culture and reagents}

The human NSCLC cell lines H1299 and A549 were purchased from ATCC and cultured in DMEM (Thermo Scientific) supplemented with $10 \%$ fetal bovine serum (Thermo Scientific) and 1\% penicillin and streptomycin at $37{ }^{\circ} \mathrm{C}$ in a humidified atmosphere containing $5 \% \mathrm{CO}_{2}$. ALO and SC79 (p-AKT agonist) [25] were purchased from Selleckchem and dissolved in Ethanol.

\section{Cell viability assay}

H1299 and A549 cells were counted and seeded at $5 \times 10^{3}$ cells/ well into each 96-well overnight for cell adhesion and treated with fresh DMEM containing ethanol or fresh DMEM with different doses $(0,0.2,0.4$, 0.8 , and $1 \mathrm{mM}$ ) of ALO for indicated time points. Then, 10ul of CCK-8 solution (MedChemExpress) was added to each well and incubated for another $1 \mathrm{~h}$ at $37{ }^{\circ} \mathrm{C}$. Measure the absorbance at $450 \mathrm{~nm}$ and $650 \mathrm{~nm}$ using a microplate reader (Thermo Scientific).

\section{Colony formation assay}

H1299 and A549 $\left(1 \times 10^{3}\right.$ cells per well $)$ were resuspended and plated in 6 -well plates. After $24 \mathrm{~h}$, cells were treated with the indicated dose of ALO for 15 days. Then, cells were fixed with $4 \%$ paraformaldehyde and stained with $0.1 \%$ crystal violet for $1 \mathrm{~h}$. Images were obtained by using a digital camera at $4 \times$ magnification.

\section{Cell apoptosis analysis}

H1299 and A549 $\left(4 \times 10^{5} /\right.$ well $)$ were seeded in 6-well plates for $24 \mathrm{~h}$ and then treated with ALO for $24 \mathrm{~h}$. Cells were harvested and washed with cold PBS, the cell pellets were then resuspended with binding buffer $(400 \mu \mathrm{l})$ and stained with Annexin V-FITC and PI (Vazyme Biotech) according to the protocols. The apoptotic cells ware analyzed by using FACS Calibur flow cytometer (BD Biosciences).

\section{Wound healing assay}

H1299 and A549 $\left(2 \times 10^{6} /\right.$ well $)$ were seeded in 6-well plates. After cells converged almost $100 \%$, scratch was made in the plate using a P200 pipette tip. The wound was generated and then washed the cells with PBS. Added medium with or without ALO to the cells and incubated for another $24 \mathrm{~h}$. The scratched area was photographed with an Olympus microscope at $0 \mathrm{~h}$ and $24 \mathrm{~h}$ with $4 \times$ magnification, respectively.

\section{Trans well cell invasion assay}

Trans well chambers (8- $\mu \mathrm{m}$ pore size Corning) were used to assay the invasive ability of the H1299 and A549. The cells $\left(4 \times 10^{4}\right.$ cells $\left./ 200 \mu \mathrm{l}\right)$ were suspended in the FBS-free DMEM and were placed in the Matrigel (BD Biosciences) pre-coated upper chamber, following which $500 \mu \mathrm{l}$ of complete DMEM containing 10\% FBS was added to the lower chamber. Following treated with or without ALO for $24 \mathrm{~h}$, the invaded cells were fixed and then stained with $0.5 \%$ Crystal violet solution for $1 \mathrm{~h}$. The stained cells were observed under a light microscope at $10 \times$ magnification, and 5 fields per chamber (insert) were observed for counting invaded cell numbers.

\section{Western blot}

H1299 and A549 cells treated with ALO for 24 h were harvested and washed with cold PBS. After that, cells were lysed with RIPA Reagent (Beyotime Biotechnology) 
supplemented with a protease inhibitor cocktail (Sigma) and incubated on ice for $30 \mathrm{~min}$. Then, the cells were centrifuged at $12,000 \times g$ for $20 \mathrm{~min}$ at $4{ }^{\circ} \mathrm{C}$. The proteins were quantified using the BCA Protein assay kit (Thermo Scientific). Equal amounts of extracts (50ug) were separated by SDS-PAGE and then were transferred onto nitrocellulose membranes for immunoblot analysis. The cytoplasmic protein was extract by PARIS ${ }^{\mathrm{TM}}$ kit protein and RNA isolation system (Thermo Scientific) for cytochrome $\mathrm{c}$ analysis. The following antibodies were used at a dilution of 1:1000 unless otherwise stated: anti- $\beta$-actin (Santa Cruz, sc-8432, 1:2000), anti-Cleaved Caspase-3 (Cell Signaling Technology, 9664), anti-Cleaved Caspase-9 (Cell Signaling Technology, 9509), anti-Cleaved PARP (Cell Signaling Technology, 94,885), anti-Cytochorome c (Cell Signaling Technology, 4850), anti-MMP-2 (Cell Signaling Technology, 40,994), anti-MMP-9 (Cell Signaling Technology, 13,667), anti-AKT (Cell Signaling Technology, 4691), anti-p-AKT (Cell Signaling Technology, 4060), anti-mTOR (Cell Signaling Technology, 2983) and anti-p-mTOR (Cell Signaling Technology, 5536).

\section{Xenograft assay}

All animal procedures were performed in accordance with protocols of the Care and Use of Laboratory Animals approved by the Animal Ethics Committee of Linyi Fourth People's Hospital. The procedure for the xenograft assay, H1299 cells $\left(2 \times 10^{6 / 100 \mu l)}\right.$ were subcutaneously injected into the right flank of 4-weeks-old BALB/C nude mice (SiPeiFu Experimental Animal). When the tumor volume reached $100 \mathrm{~mm}^{3}$, the animals were randomly divided into Mock group and ALO treatment group, 10 mice in each group. The ALO treatment group was given intraperitoneal injection of ALO at a dose of $30 \mathrm{mg} / \mathrm{kg}$ and the Mock group was given intraperitoneal injection of normal saline at equal volume for 15 consecutive days, and all the mice were sacrificed 28 days later. The euthanasia method was followed as using one hand to hold the animal and tilt the animal slightly downward so that its head lower than its abdomen, injects sodium pentobarbital $(200 \mathrm{mg} / \mathrm{kg})$ into the caudal left quadrant. Tumor volumes were measured every day and calculated using the formula: volume $=0.5 \times$ length $\times$ width $^{2}$.

\section{Statistical analysis}

All data are expressed as the mean \pm S.D. of three or more experiments and analyzed by Graphpad Prism 5.0 software (Graphpad software Inc., CA, USA). Statistical significance was determined with the two-tailed Student's t-test. The significance was determined: ${ }^{*} \mathrm{P}<0.05, \# \mathrm{P}<0.05$ and $\& \mathrm{P}<0.05$, with NS indicating no significance.

\section{Results}

\section{ALO suppresses cell proliferation and self-renewal}

To evaluate whether ALO treatment suppresses cell growth in NSCLC cells, H1299 and A549 cells were treated with different concentrations of $\operatorname{ALO}(0,0.2,0.40 .8$ and $1.6 \mathrm{mM})$ for 24,48 and $72 \mathrm{~h}$ respectively. Then the cell viability was determined using CCK8 assay. ALO inhibited the proliferation of both $\mathrm{H} 1299$ and A549 cells in dose-dependent manners (Fig. 1A). Moreover, the 50\% inhibitive concentration (IC50) values of ALO were calculated. The IC50 values in H1299 and A549 cells were around $0.8 \mathrm{mM}$ and $0.6 \mathrm{mM}$ after ALO treatment for $72 \mathrm{~h}$, respectively. Therefore, we selected $0.4 \mathrm{mM}$ and $0.8 \mathrm{mM}$ for $\mathrm{H} 1299$ cells, $0.3 \mathrm{mM}$ and $0.6 \mathrm{mM}$ for A549 cells treatment in the following experiments. In addition, colony formation assay confirmed that the effect of ALO on cell self-renewal of both cell lines, compared to untreated cells, ALO treatment inhibited the colony formation capacities of both H1299 and A549 cells in a dosedependent fashion (Fig. 1B). Therefore, the results indicate that ALO suppresses the proliferation and self-renewal in both A549 and H1299 NSCLC cells.

\section{ALO induces apoptosis in NSCLC cells via intrinsic apoptotic pathway}

To investigate whether ALO inhibits the cell viability via apoptosis induced in NSCLC cells. Apoptosis analysis was conducted in $\mathrm{H} 1299$ and A549 cells following ALO treatment for $24 \mathrm{~h}$. The percentage of apoptotic cells both increased with a dose dependent fashion in H1299 and A549 cells (Fig. 2A). To explore the underlying mechanisms of ALO induced apoptosis in NSCLC cells, the expression levels of cytochrome $c$ and the cleavage of caspase-3, caspased-9 and PARP were subsequently measured by Western blot, which are the key regulators of the intrinsic apoptotic pathway [26]. ALO treatment significantly enhanced the level of cytochrome $c$ in cytosol, and resulted in the dramatical increased levels of the cleaved caspase-3, caspased-9 and PARP (Fig. 2B). These findings reveal that ALO induces apoptosis in NSCLC cells via intrinsic apoptotic pathway.

\section{ALO attenuates the migration and invasion in in NSCLC cells by downregulating MMPs}

To explore whether ALO treatment also affects the migration and invasion abilities in NSCLC cells, we performed wound healing and transwell invasion assay. Wound healing assay showed that ALO treatment for 24 h significantly attenuated cell migration in H1299 and A549 cells in a dose dependent fashion (Fig. 3A). Further, transwell assay indicated that ALO treatment inhibited the invasion of NSCLC cells transit from the matrigelcoated membrane in a dose-dependent manner (Fig. 3B). The MMP-2 and MMP-9 play important roles in the 

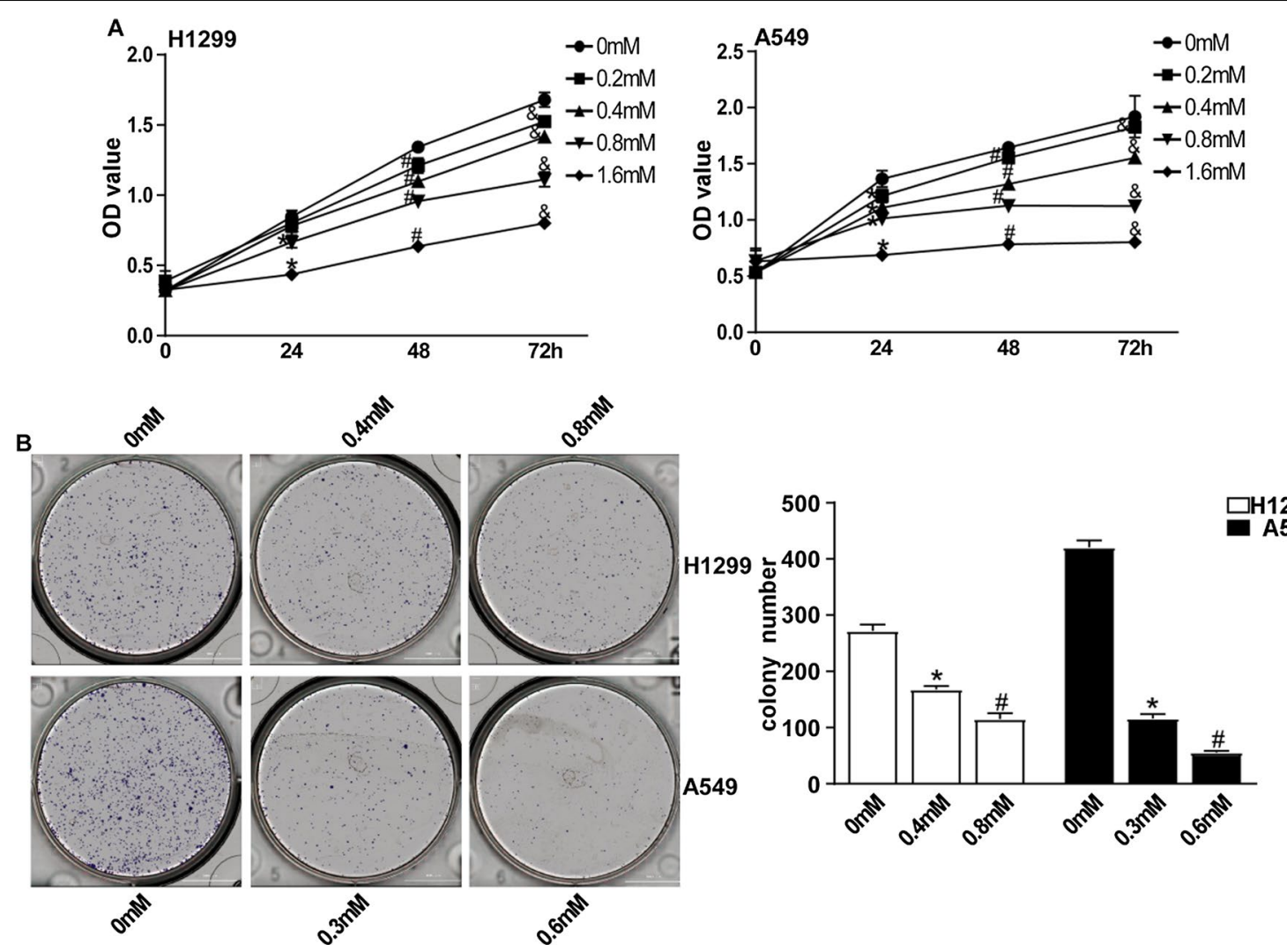

Fig. 1 Inhibition effect of ALO on the proliferation and self-renewal of NSCLC cells. A H1299 and A549 cells were treated with ALO for 24, 48 and $72 \mathrm{~h}$ at $0.2,0.4,0.8$ and $1.6 \mathrm{mM}$, respectively, cells proliferation was detected by CCK8 assay. ${ }^{*} \mathrm{P}<0.05$, the ALO group $(0.2,0.4,0.8$ and $1.6 \mathrm{mM})$ compared to the control group ( $0 \mathrm{mM}$, solvent ethanol) at $24 \mathrm{~h}$; $\# \mathrm{P}<0.05$, the $\mathrm{ALO}$ group $(0.2,0.4,0.8$ and $1.6 \mathrm{mM})$ compared to the control group (0 mM, solvent ethanol) at $48 \mathrm{~h} ; \& \mathrm{P}<0.05$, the $\mathrm{ALO}$ group $(0.2,0.4,0.8$ and $1.6 \mathrm{mM})$ compared to the control group $(0 \mathrm{mM}$, solvent ethanol) at $72 \mathrm{~h}$. B H1299 and A549 cells were treated with the indicated dose of ALO, the colony formation viability was evaluated by clonogenic formation assay. ${ }^{*} \mathrm{P}<0.05$, compared to the control group $(0 \mathrm{mM}$, solvent ethanol); $\# \mathrm{P}<0.05$, compared to the ALO group $(0.4 \mathrm{mM}$ or $0.3 \mathrm{mM})$. Data are from one experiment representative of three experiments. Two-tailed Student's test

invasion and metastasis of NSCLC cells. Therefore, we examined the levels of MMP-2 and MMP-9 after treating with ALO by western blot. The following treatment with ALO for $24 \mathrm{~h}$, western blot analysis revealed that the levels of MMP-2 and MMP-9 were markedly reduced in both A549 and H1299 cells (Fig. 3C). These data indicates that ALO suppresses the migration and invasion of A549 and H1299 cells by downregulated of MMP-2 and MMP-9 expression.

\section{ALO inhibits PI3K/AKT/ mTOR signaling pathway}

$\mathrm{PI} 3 \mathrm{~K} / \mathrm{AKT} / \mathrm{mammalian}$ target of rapamycin (mTOR) pathway is one of the most frequently activated signaling pathways in NSCLC $[27,28]$, and is involved in cell apoptosis as well as invasion. To explore whether administration of ALO affects this pathway, H1299 and A549 cells were treated with or without different concentrations of ALO for $24 \mathrm{~h}$, and the status p-Akt and p-mTOR were determined by western blot. The phosphorylation of
Akt and mTOR were reduced after ALO treatment, however, the expression of Akt and mTOR were unchanged by ALO treatment (Fig. 4). The results suggest that ALO might induce apoptosis and invasion of NSCLC cells by inhibiting PI3K pathway.

\section{ALO influence cell proliferation and apoptosis through PI3K/AKT pathway}

In order to further verify ALO suppresses cell growth and induces apoptosis through PI3K/AKT pathway, H1299 and A549 cells were treated with $0.4 \mathrm{mM}$ or $0.3 \mathrm{mM}$ of ALO plus 10uM SC79, a p-AKT agonist, for $24 \mathrm{~h}$ respectively. The CCK8 assay results showed that SC79 reversed the inhibition of proliferation by ALO for H1299 and A549 cells (Fig. 5A). And the flow cytometry analysis indicated $\mathrm{SC} 79$ reversed the induction of apoptosis by ALO (Fig. 5B). These results reveal that ALO could induce apoptosis in NSCLC cells via PI3K/AKT signal pathway. 


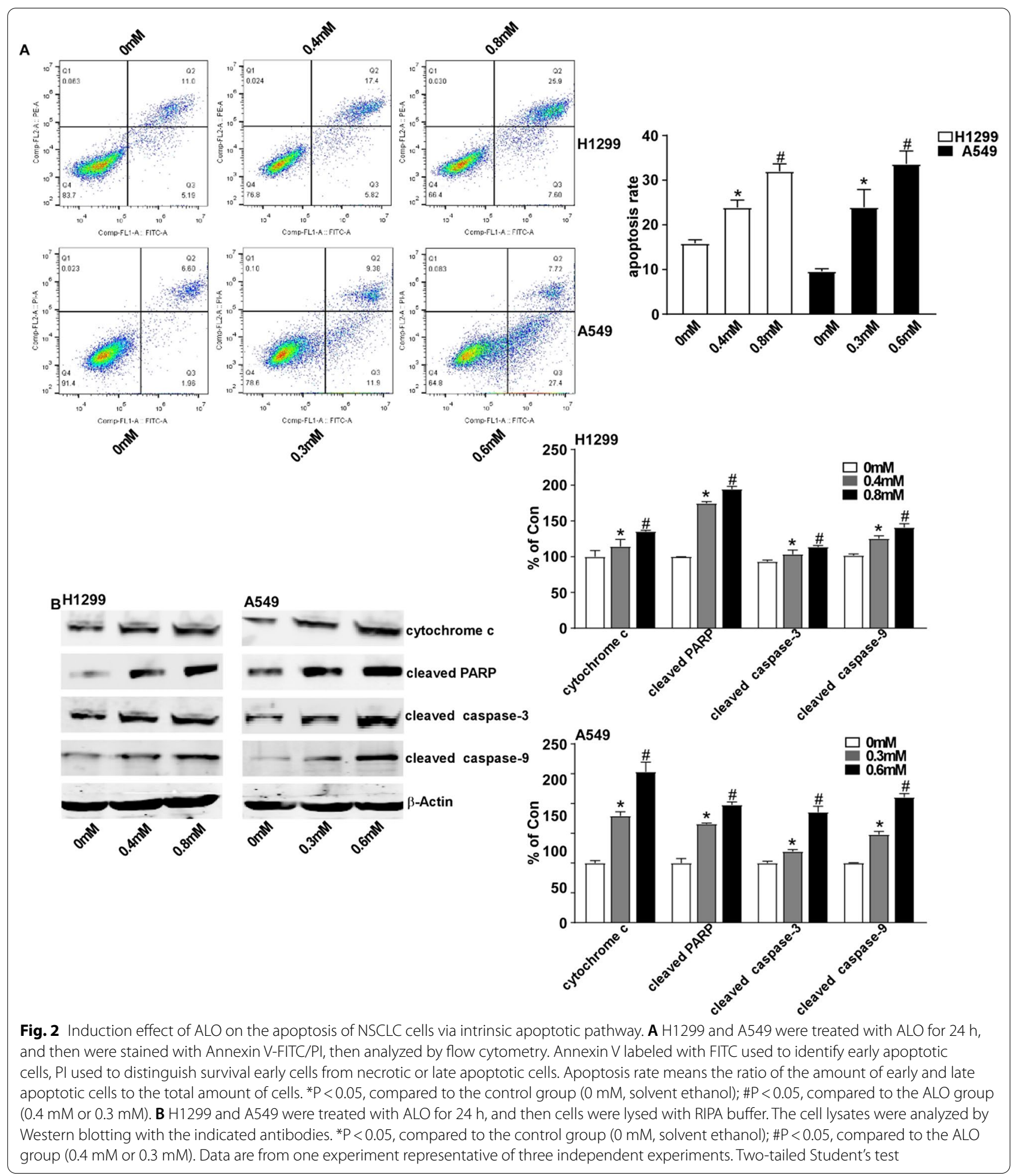




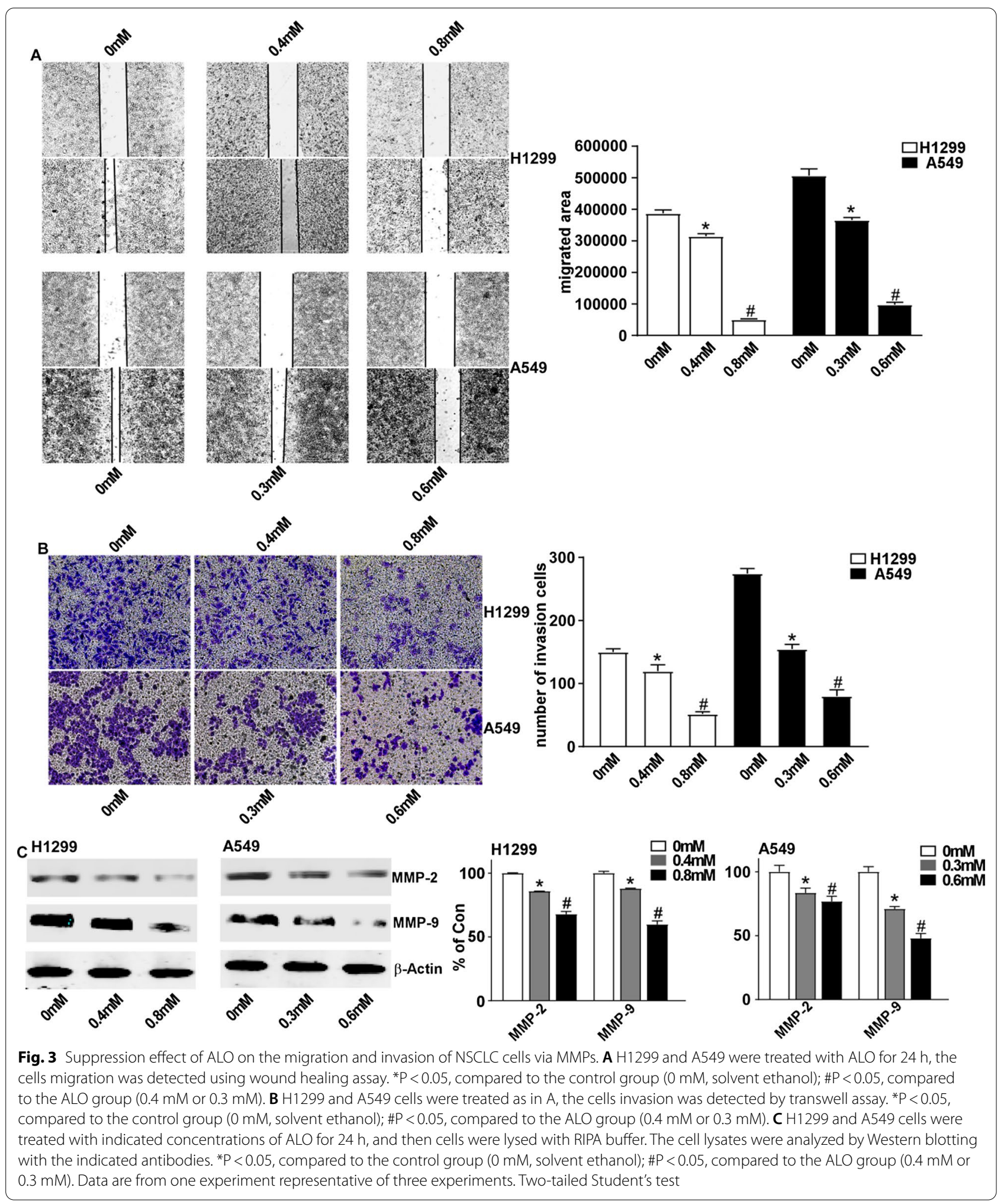




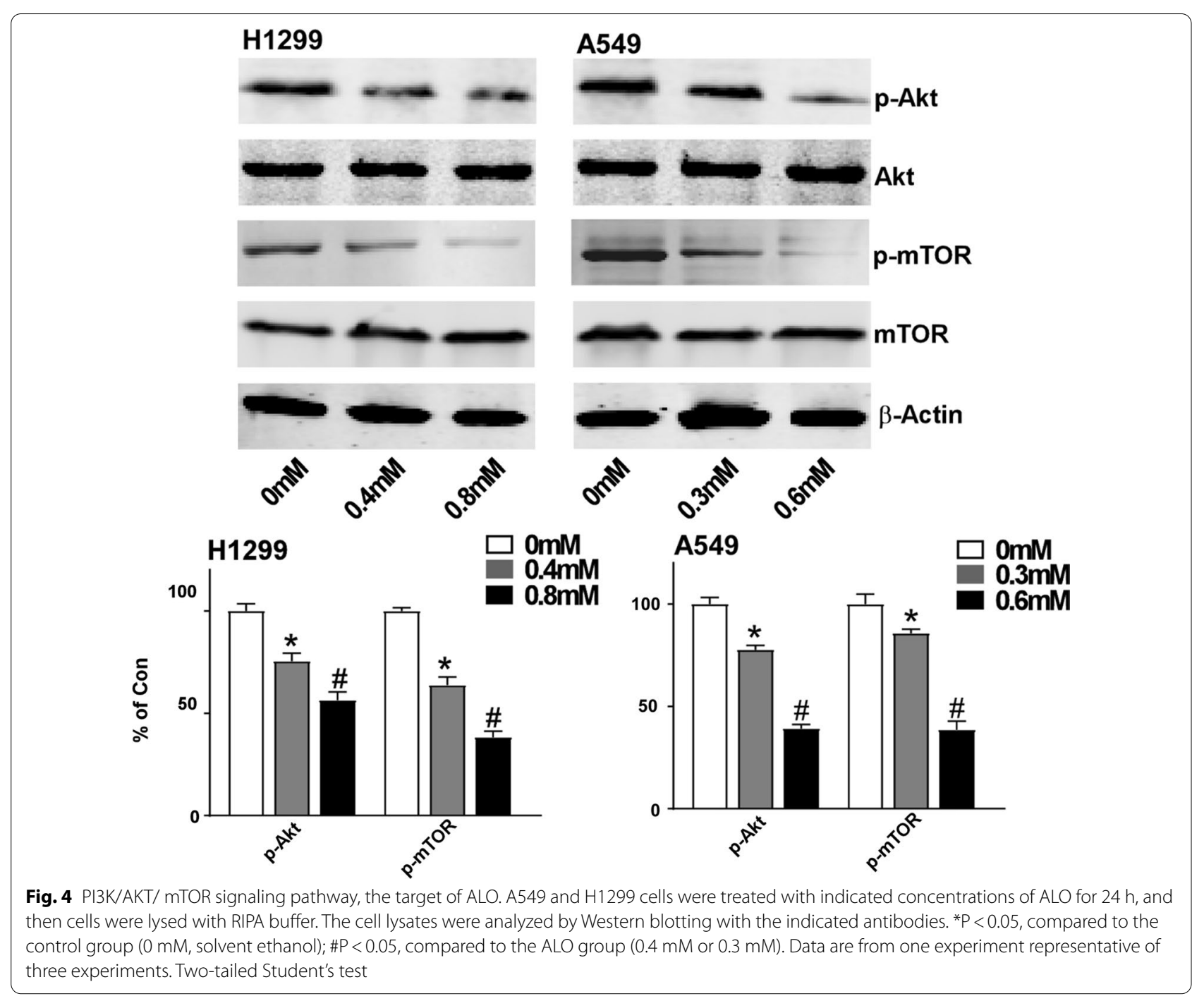

\section{ALO attenuates the migration and invasion through PI3K/ AKT pathway}

In order to further certify ALO treatment also affects the migration and invasion in NSCLC cells through PI3K/AKT pathway, the NSCLC cells were treated with of ALO plus SC79. Wound healing assay showed that SC79 treatment significantly reversed the cell migration inhibited by ALO in H1299 and A549 cells (Fig. 6A). Further, transwell assay indicated that SC79 treatment also reversed the inhibition of $\mathrm{H} 1299$ and A549 cells invasion by ALO (Fig. 6B). These datas indicate that ALO could suppress the migration and invasion of NSCLC cells by affecting PI3K/AKT signal pathway.

\section{ALO suppresses the growth of NSCLC in vivo}

To further explore the function of ALO on tumor growth in vivo, A549 cells were used to perform xenograft tumor formation assay. The results revealed that ALO obviously

(See figure on next page.)

Fig. 5 Inflorescence of ALO on the proliferation and apoptosis through PI3K/AKT pathway. A H1299 and A549 cells were treated $0.4 \mathrm{mM}$ or $0.3 \mathrm{mM}$ ALO with or without $10 \mathrm{uM} \mathrm{SC79}$ for $24 \mathrm{~h}$, respectively. Cells proliferation was detected by CCK8 assay. ${ }^{*} \mathrm{P}<0.05$, compared to the mock group (solvent ethanol) at $24 \mathrm{~h}$; $\mathrm{P}<0.05$, compared to the ALO group (0.4 mM or $0.3 \mathrm{mM}$ ). B H1299 and A549 cells were treated $0.4 \mathrm{mM}$ or $0.3 \mathrm{mM}$ ALO with or without $10 \mathrm{uM} \mathrm{SC79}$ for $24 \mathrm{~h}$, respectively, and then were stained with annexin V/PI, then analyzed by flow cytometry. ${ }^{*} \mathrm{P}<0.05$, compared to the mock group (solvent ethanol); $\# \mathrm{P}<0.05$, compared to the ALO group $(0.4 \mathrm{mM}$ or $0.3 \mathrm{mM}$ ). Data are from one experiment representative of three experiments. Two-tailed Student's test 


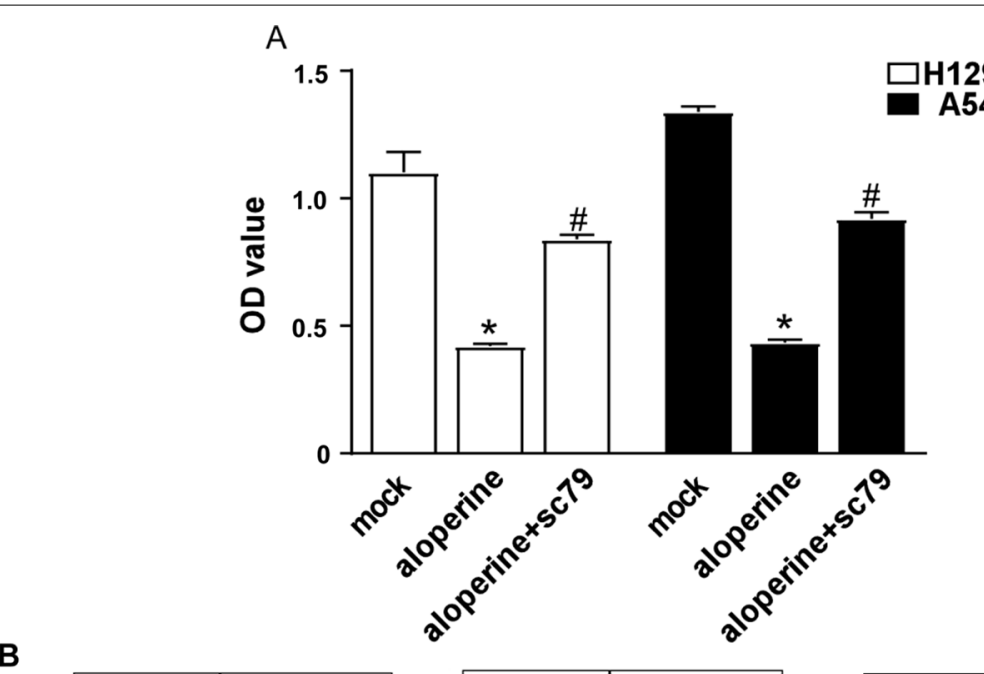

B
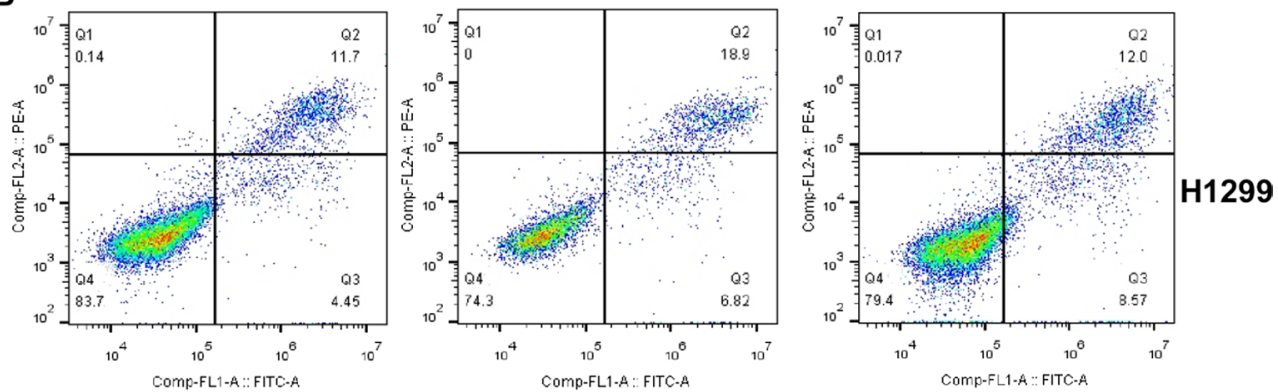

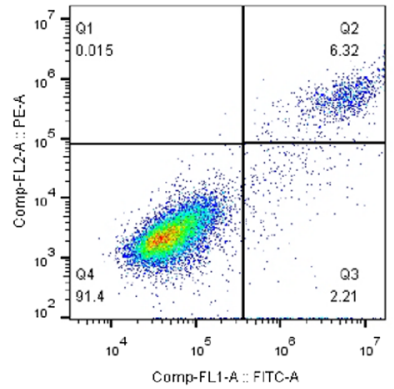

mock$$
\text { 高竞, }
$$

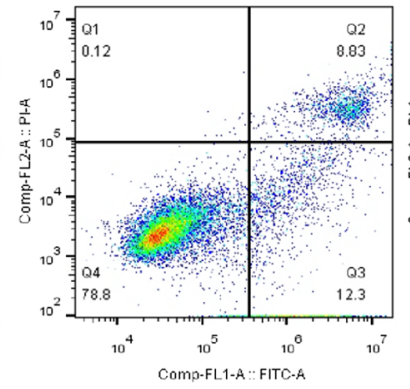

aloperine

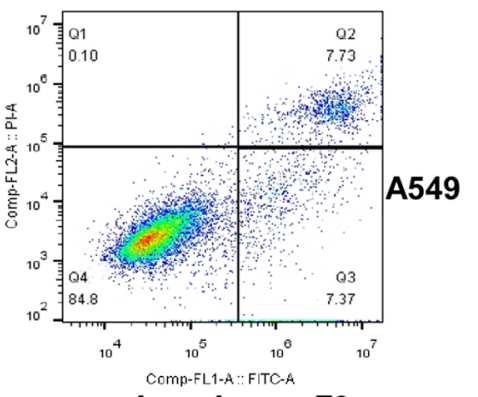

aloperine+sc79

$\square$ H1299

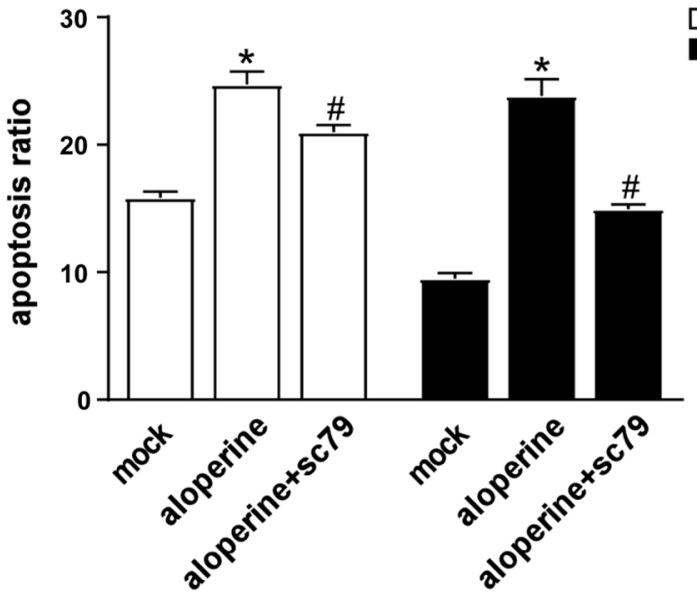

Fig. 5 (See legend on previous page.) 


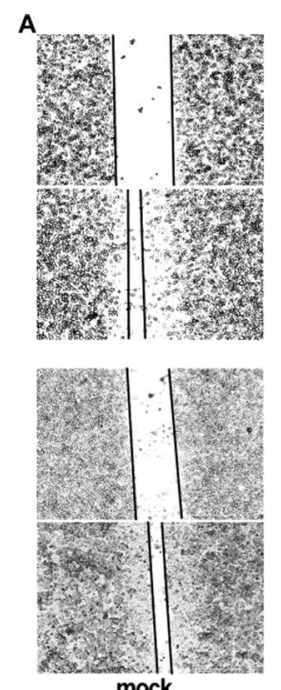

mock

B

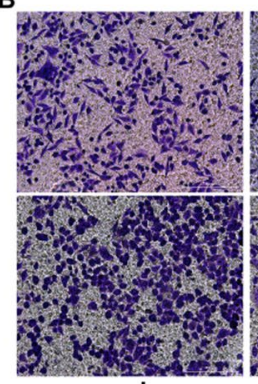

mock
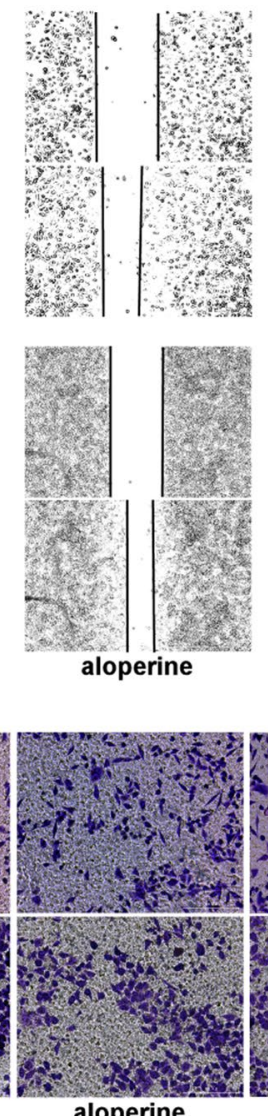

aloperine
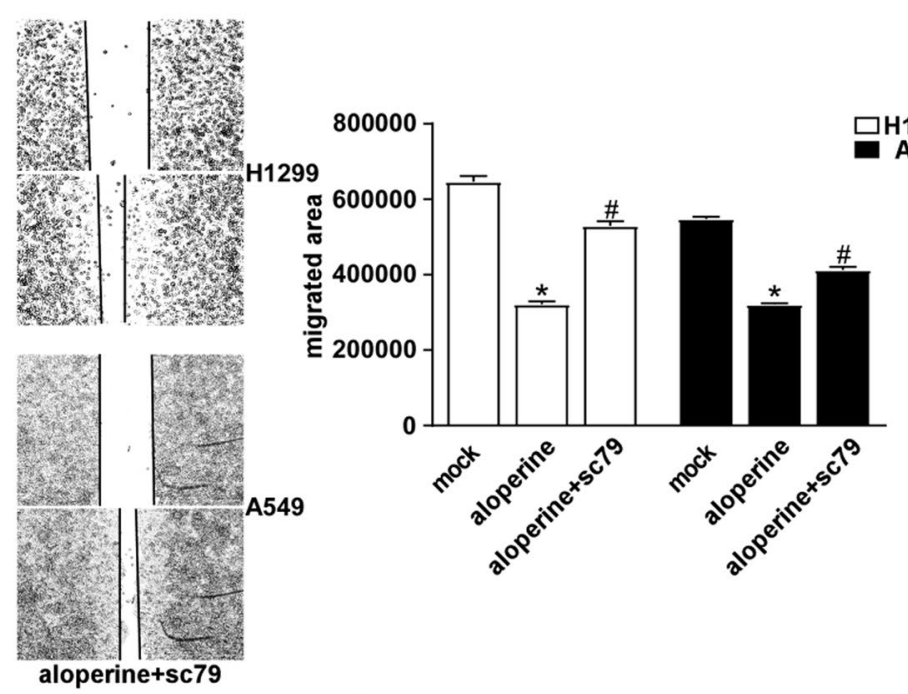

aloperine+sc79
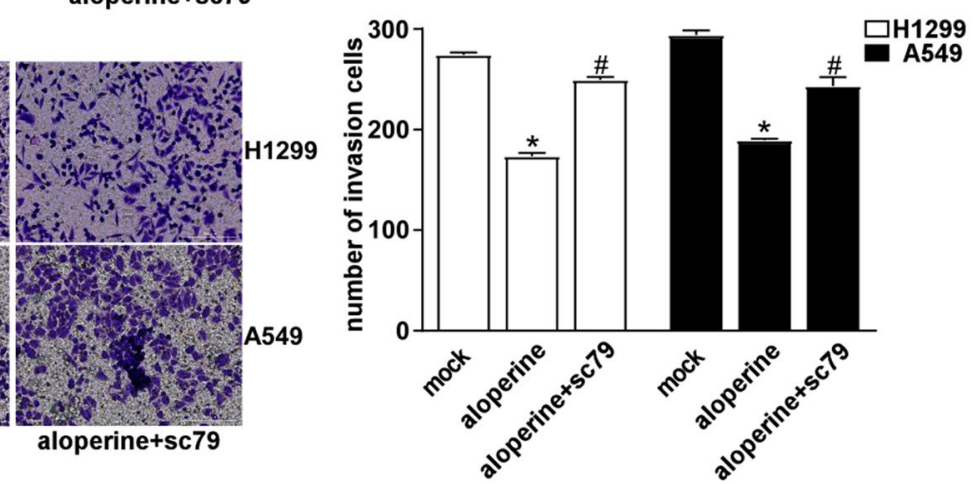

Fig. 6 Inflorescence of ALO on the migration and invasion through PI3K/AKT pathway. A H1299 and A549 cells were treated $0.4 \mathrm{mM}$ or $0.3 \mathrm{mM}$ ALO with or without $10 \mathrm{UM} \mathrm{SC79}$ for $24 \mathrm{~h}$, respectively. The cell migration was detected using wound healing assay. ${ }^{*} \mathrm{P}<0.05$, compared to the mock group (solvent ethanol) at $24 \mathrm{~h}$; $\mathrm{AP}<0.05$, compared to the ALO group ( $0.4 \mathrm{mM}$ or $0.3 \mathrm{mM}$ ). $\mathbf{B} \mathrm{H} 1299$ and A549 cells were treated $0.4 \mathrm{mM}$ or $0.3 \mathrm{mM}$ ALO with or without $10 \mathrm{uM} \mathrm{SC79}$ for $24 \mathrm{~h}$, respectively, and the cell invasion was detected by transwell assay. ${ }^{*} \mathrm{P}<0.05$, compared to the mock group (solvent ethanol); $\# \mathrm{P}<0.05$, compared to the $\mathrm{ALO}$ group $(0.4 \mathrm{mM}$ or $0.3 \mathrm{mM}$ ). Data are from one experiment representative of three experiments. Two-tailed Student's test

reduced the tumor volume compared to the mock group (Fig. 7A), Moreover, ALO significantly suppressed tumor weight in comparison with mock group (Fig. 7B). Furthermore, the tumors treated with ALO grew more slowly than the mock group (Fig. 7C). These findings showed that ALO inhibited the growth of NSCLC in vivo.

Since ALO induced apoptosis and inhibited invasion of NSCLC cells by inhibiting PI3K/AKT pathway, the effect of tumor growth inhibition by ALO in vivo should be mediated via $\mathrm{p}$-AKT. The p-Akt and p-mTOR of xenograft tumor were determined by western blot. The phosphorylation of Akt and mTOR were also reduced after ALO treatment (Fig. 7D). The results indicated that ALO also inhibited PI3K/AKT pathway in vivo.

\section{Discussion}

Accumulating evidence has indicated that ALO exerts anti-tumor effects on various cancers cells, including leukemia cell lines (HL-60, U937, and K562), esophageal cancer cells (EC109), lung cancer cells (A549), hepatocellular carcinoma cells (HepG2), colon cancer cells (SW480 and HCT116) and osteosarcoma cells (MG-63 and U2OS) $[10,11,29]$. However, the precise molecular mechanism of ALO exerting anti-tumor effects on NSCLC is undefined. In this study, we showed that that ALO inhibited the NSCLC progression in vivo and in vitro. ALO effectively inhibited the proliferation and the clonogenic survival by promoting apotosis in NSCLC. Cell apoptotic effects of ALO were correlated with the activation of caspases family. ALO also suppressed the migration and invasion of NSCLC and this effect was associated with the 

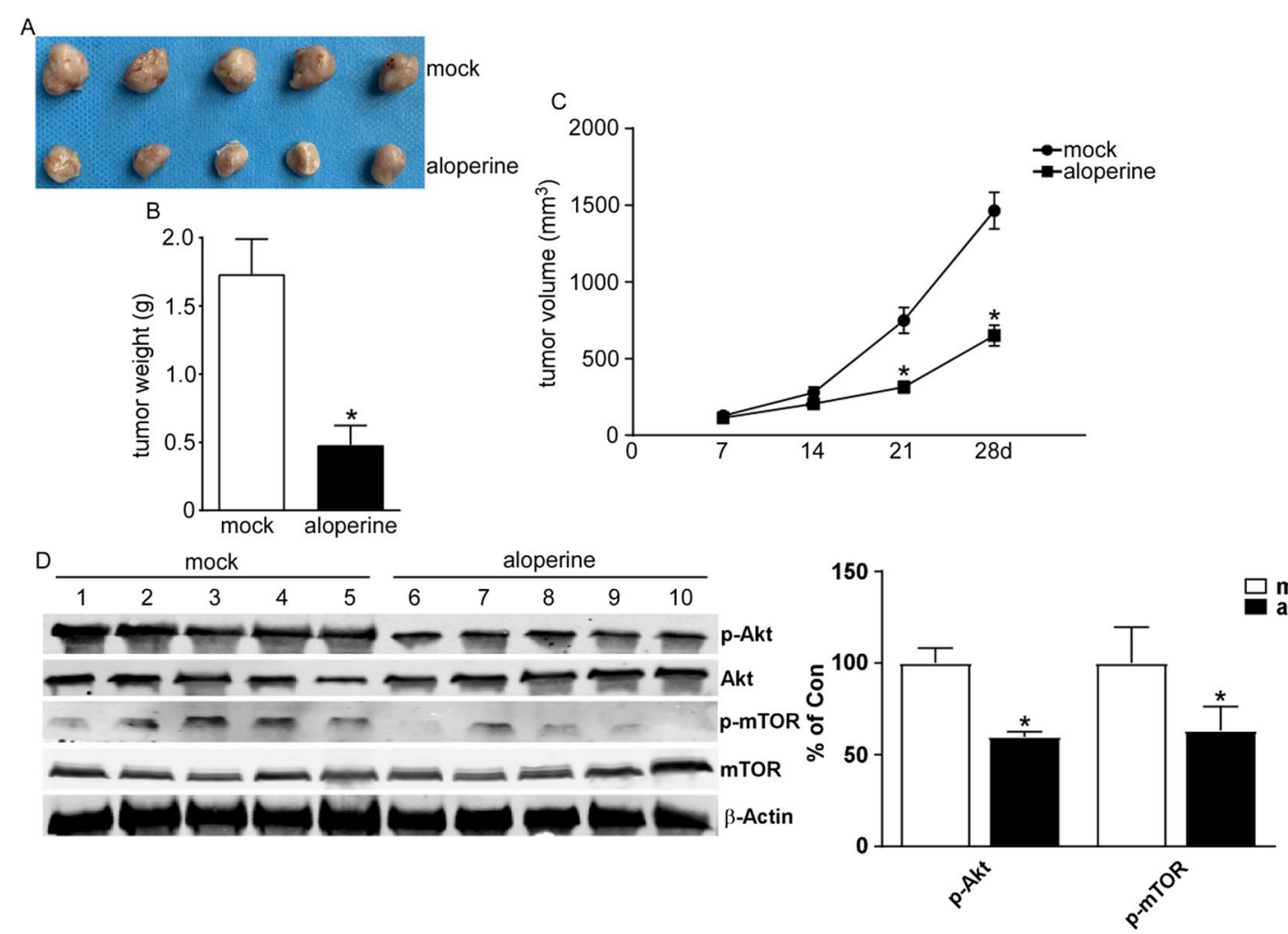

Fig. 7 Suppression effect of ALO on tumor growth in vivo. A Representative tumors images of xenograft mice treated with ALO (30 mg/kg) or normal saline. B ALO group displayed a low weight of tumors compared to mock group. ${ }^{*} \mathrm{P}<0.05$, compared to the mock group (normal saline). $\mathbf{C}$ The tumors of ALO group showed a more slow growth compared to mock group. ${ }^{*} \mathrm{P}<0.05$, compared to the mock group (normal saline) at $21 \mathrm{~d}$; $\# P<0.05$, compared to the mock group (normal saline) at 28d. D WB images of representative tumors. Small part of xenograft tumor tissue was lysed with RIPA buffer. The tissue lysates were analyzed by Western blotting with the indicated antibodies. ${ }^{*} P<0.05$, compared to the mock group (normal saline). Two-tailed Student's test

reduced expression of MMP-2 and MMP-9. Moreover, ALO-induced apoptosis and invasion may be involved in the PI3K/Akt signaling pathway, SC79 as a p-AKT agonist reversed the tumor suppressor function of ALO. SA-49, a new novel aloperine derivative, induced MITF-dependent lysosomal degradation of PD-L1 and suppressed Lewis tumor xenograft growth by activating immune microenvironment in C57BL/6 mice [30]. The current research on SA49 was only limited to antibody-based PD-1/PD-L1 inhibitors for NSCLC, but SA49 maybe became a more reliable and effective anti-tumor compound as the most potential derivative of ALO soon.

Apoptosis refers to a highly regulated physiological process of cell death. Cell apoptosis mainly includes intrinsic pathway (the mitochondrial pathway) and extrinsic pathway (death receptor pathway) [31]. Mitochondria plays a vital role in apoptotic pathway and the mitochondrial dysfunction that occurs during apoptosis [32]. The rupture of mitochondria outer membrane results in the release of cytochrome $\mathrm{c}$ into the cytosol. Cytochrome c, together with Apaf-1, forms a heptametrical complex called an apoptosome, resulting in the activation of caspase-9 (initiator caspase) and consequently caspase-3 (executioner caspase). Activated capspase-3 then cleaves PARP, which is known as a marker of apoptosis [33]. Our results showed that ALO activated caspase- 9 and caspase-3, as well as PARP, demonstrating that ALO induces apoptosis in NSCLC via the mitochondrial apoptotic pathway. Interestingly, ALO also induces the activation of caspase- 9 and caspase- 3 in osteosarcoma and hepatocellular carcinoma cells $[9,10]$. This indicates that ALO exerts similar anti-tumor functions in different cancer cells.

In addition to apoptosis, necroptosis is an alternative programmed cell death, which is different from apoptosis and that it is regulated by receptor interacting protein kinase-1(RIPK1), RIPK3, and mixed lineage kinase domainlike (MLKL) [34]. Necroptotic pathway may be involved in tumorigenesis [35]. More importantly, Shikonin, is the major constituent of the root of Lithospermum erythrorhizon, could promote RIP1-dependent cell death in cancer 
cells [36]. Whether ALO can also induce necroptosis in NSCLC will need to be investigated in future.

The distant metastasis is the main cause of morbidity and mortality in patients with cancer [37]. Despite there has been enormous progress in management of NSCLC, survival rates have not improved significantly. More than $79 \%$ of all lung cancer patients develop metastases, and the 5-year survival rate of patients with distant metastases is $<5 \%$ [38]. Therefore, we conducted wound healing and transwell invasion assay to investigate the influence of ALO on A549 and H1299 cells. Our results indicated that ALO suppressed cell migration and invasion in both cell lines. MMPs are zinc-dependent proteolytic enzymes involved in the degradation of extracellular matrix, such as collagen, fibrinogen and proteoglycan. The expression of MMP-2 and MMP-9 was significantly increased in patients with malignant tumors [39], more importantly, MMP-2 and MMP-9 are essential in in NSCLC invasion and metastasis. Therefore, we explored the expression of MMP-2 and MMP-9 after ALO treatment in A549 and $\mathrm{H} 1299$ cells. Our data showed that ALO reduced the expression levels of MMP-2 and MMP-9, suggesting the anti-migrating and anti-invasive roles of ALO in NSCLC.

The underlying mechanisms for ALO-induced anti-tumor effects on lung cancer are well unknown. Muhammed et al. demonstrated that the ALO treatment on NSCLC cells and xenograft model produced antiproliferative effects, induced apoptosis, and arrested cell cycle at the G1 phase, and the p53/p21 pathway involved in the mechanism [40]. The PI3K/Akt/mTOR signaling pathway has been also implicated in tumor cell proliferation, metastasis and apoptosis [20,21]. Accumulating evidences suggest that targeting the Akt/mTOR pathway is promising for the treatment of NSCLC [20]. In this study, we found that ALO treatment on NSCLC cells and xenograft model reduced the phosphorylation of Akt and mTOR, but had no effects on the expression of Akt and mTOR. In addition to cancer, the mTOR pathway plays critical roles in the pathogenesis of autoimmune diseases [41] and infectious diseases [42, 43]. Thus, we hypothesized that ALO may be introduced for the treatment of autoimmune and infectious diseases, such as HIV and HBV infection. Interestingly, PP2A was reported to be involved in regulating of Akt activities [44, 45]. PP2A may directly interact with Akt that suppresses PI3K signaling pathway after ALO treatment. Whether PP2A is a direct target of ALO, further studies are needed to investigate.

In summary, our present results suggest that ALO induces apoptosis and invasion in NSCLC through the $\mathrm{PI} 3 \mathrm{~K} / \mathrm{Akt} / \mathrm{mTOR}$ signaling pathway. Our study provides a new insight into the use of ALO in the treatment of NSCL.

\section{Authors' contributions}

$\mathrm{HL}$ conceived and designed the experiments; FL and TL performed the experiments; FL, TL and HL analyzed and contributed reagents /materials /analysis tools; $\mathrm{FL}$ and $\mathrm{HL}$ wrote the paper. All authors read and approved the final manuscript.

\section{Funding}

Not applicable.

\section{Availability of data and materials}

The raw materials and data are available from the corresponding author upon reasonable request.

\section{Declarations}

Ethics approval and consent to participate

All animal protocols were approved by the Institutional Ethics Committee on Animal Research of Linyi Fourth People's Hospital.

\section{Consent for publication}

All authors reviewed the manuscript and consent to publish in this journal.

\section{Competing interests}

The authors declare no potential conflicts of interest.

\section{Author details}

1Department of Pharmacy, Linyi Fourth People's Hospital, No. 121, Qianshi Ave., Linyi 276005, Shandong, China. ${ }^{2}$ Department of Pediatrics, Linyi Fourth People's Hospital, No. 121, Qianshi Ave., Linyi 276005, Shandong, China. ${ }^{3}$ Department of Ultrasound, Qilu Hospital of Shandong University, No. 107, Wenhuaxi Rd., Jinan 250012, Shandong, China.

Received: 27 July 2021 Accepted: 24 November 2021

Published online: 11 December 2021

\section{References}

1. Bray F, Ferlay J, Soerjomataram I, Siegel RL, Torre LA, Jemal A. Global cancer statistics 2018: GLOBOCAN estimates of incidence and mortality worldwide for 36 cancers in 185 countries. CA Cancer J Clin. 2018;68(6):394-424.

2. Molina JR, Yang P, Cassivi SD, Schild SE, Adjei AA. Non-small cell lung cancer: epidemiology, risk factors, treatment, and survivorship. Mayo Clin Proc. 2008;83(5):584-94.

3. Fulda S. Modulation of apoptosis by natural products for cancer therapy. Planta Med. 2010;76(11):1075-9.

4. Yuan XY, Liu W, Zhang P, Wang RY, Guo JY. Effects and mechanisms of aloperine on 2,4-dinitrofluorobenzene-induced allergic contact dermatitis in BALB/c mice. Eur J Pharmacol. 2010;629(1-3):147-52.

5. Lin WC, Lin JY. Five bitter compounds display different anti-inflammatory effects through modulating cytokine secretion using mouse primary splenocytes in vitro. J Agric Food Chem. 2011;59(1):184-92.

6. Wang $\mathrm{C}$, Choi YH, Xian Z, Zheng M, Piao H, Yan G. Aloperine suppresses allergic airway inflammation through NF-kappaB, MAPK, and $\mathrm{Nrf2/HO}-1$ signaling pathways in mice. Int Immunopharmacol. 2018;65:571-9.

7. Zhang X, Lv XQ, Tang S, Mei L, Li YH, Zhang JP, Jiang JD, Peng ZG, Song DQ. Discovery and evolution of aloperine derivatives as a new family of HCV inhibitors with novel mechanism. Eur J Med Chem. 2018;143:1053-65.

8. Dang Z, Xie H, Zhu L, Zhang Q, Li Z, Huang L, Chen CH. Structure optimization of aloperine derivatives as HIV-1 entry inhibitors. ACS Med Chem Lett. 2017;8(11):1199-203.

9. Liu JS, Huo CY, Cao HH, Fan CL, Hu JY, Deng LJ, Lu ZB, Yang HY, Yu LZ, Mo ZX, et al. Aloperine induces apoptosis and G2/M cell cycle arrest in hepatocellular carcinoma cells through the PI3K/Akt signaling pathway. Phytomed Int J Phytotherapy Phytopharmacol. 2019;61: 152843. 
10. Chen S, Jin Z, Dai L, Wu H, Wang J, Wang L, Zhou Z, Yang L, Gao W. Aloperine induces apoptosis and inhibits invasion in MG-63 and U2OS human osteosarcoma cells. Biomed Pharmacother. 2018;97:45-52.

11. Zhang L, Zheng Y, Deng H, Liang L, Peng J. Aloperine induces G2/M phase cell cycle arrest and apoptosis in HCT116 human colon cancer cells. Int J Mol Med. 2014;33(6):1613-20.

12. Tian D, Li Y, Li X, Tian Z. Aloperine inhibits proliferation, migration and invasion and induces apoptosis by blocking the Ras signaling pathway in human breast cancer cells. Mol Med Rep. 2018;18(4):3699-710.

13. Fulda S, Debatin KM. Extrinsic versus intrinsic apoptosis pathways in anticancer chemotherapy. Oncogene. 2006;25(34):4798-811.

14. Fulda S. Targeting apoptosis for anticancer therapy. Semin Cancer Biol. 2015:31:84-8.

15. Wong RS. Apoptosis in cancer: from pathogenesis to treatment. J Exp Clin Cancer Res CR. 2011;30:87.

16. Annis MG, Soucie EL, Dlugosz PJ, Cruz-Aguado JA, Penn LZ, Leber $B$, Andrews DW. Bax forms multispanning monomers that oligomerize to permeabilize membranes during apoptosis. EMBO J. 2005;24(12):2096-103.

17. Yuan J, Zhang G, Li X, Ma Q, Cheng W, Wang W, Zhang B, Hu T, Song G Knocking down USP39 inhibits the growth and metastasis of non-smallcell lung cancer cells through activating the p53 pathway. Int J Mol Sci. 2020. https://doi.org/10.3390/ijms21238949.

18. Rollin J, Regina S, Vourc'h P, lochmann S, Blechet C, Reverdiau P, Gruel Y. Influence of MMP-2 and MMP-9 promoter polymorphisms on gene expression and clinical outcome of non-small cell lung cancer. Lung Cancer (Amsterdam, Netherlands). 2007:56(2):273-80.

19. Dong QZ, Wang Y, Tang ZP, Fu L, Li QC, Wang ED, Wang EH. Derlin-1 is overexpressed in non-small cell lung cancer and promotes cancer cell invasion via EGFR-ERK-mediated up-regulation of MMP-2 and MMP-9. Am J Pathol. 2013;182(3):954-64.

20. Fumarola C, Bonelli MA, Petronini PG, Alfieri RR. Targeting PI3K/AKT/ mTOR pathway in non small cell lung cancer. Biochem Pharmacol. 2014;90(3):197-207.

21. Mayer IA, Arteaga CL. The PI3K/AKT pathway as a target for cancer treatment. Annu Rev Med. 2016;67:11-28.

22. Tsurutani J, Fukuoka J, Tsurutani H, Shih JH, Hewitt SM, Travis WD, Jen J, Dennis PA. Evaluation of two phosphorylation sites improves the prognostic significance of Akt activation in non-small-cell lung cancer tumors. J Clin Oncol. 2006;24(2):306-14.

23. Brognard J, Clark AS, Ni Y, Dennis PA. Akt/protein kinase B is constitutively active in non-small cell lung cancer cells and promotes cellular survival and resistance to chemotherapy and radiation. Cancer Res. 2001;61(10):3986-97.

24. Schuurbiers OC, Kaanders JH, van der Heijden HF, Dekhuijzen RP, Oyen WJ, Bussink J. The PI3-K/AKT-pathway and radiation resistance mechanisms in non-small cell lung cancer. J Thorac Oncol. 2009;4(6):761-7.

25. Li S, Wu Z, Tantray I, Li Y, Chen S, Dong J, Glynn S, Vogel H, Snyder M, Lu B. Quality-control mechanisms targeting translationally stalled and C-terminally extended poly(GR) associated with ALS/FTD. Proc Natl Acad Sci U S A. 2020;117(40):25104-15.

26. Shalini S, Dorstyn L, Dawar S, Kumar S. Old, new and emerging functions of caspases. Cell Death Differ. 2015:22(4):526-39.

27. Balsara BR, Pei J, Mitsuuchi Y, Page R, Klein-Szanto A, Wang H, Unger M, Testa JR. Frequent activation of AKT in non-small cell lung carcinomas and preneoplastic bronchial lesions. Carcinogenesis. 2004;25(11):2053-9.

28. Beck JT, Ismail A, Tolomeo C. Targeting the phosphatidylinositol 3-kinase (PI3K)/AKT/mammalian target of rapamycin (mTOR) pathway: an emerging treatment strategy for squamous cell lung carcinoma. Cancer Treat Rev. 2014:40(8):980-9.

29. Lin Z, Huang CF, Liu XS, Jiang J. In vitro anti-tumour activities of quinolizidine alkaloids derived from Sophora flavescens Ait. Basic Clin Pharmacol Toxicol. 2011;108(5):304-9.

30. Zhang N, Dou YY, Liu L, Zhang X, Liu XJ, Zeng QX, Liu Y, Yin MX, Liu XJ, Deng HB, et al. SA-49, a novel aloperine derivative, induces MITF-dependent lysosomal degradation of PD-L1. EBioMedicine. 2019:40:151-62.

31. Riedl SJ, Salvesen GS. The apoptosome: signalling platform of cell death. Nat Rev Mol Cell Biol. 2007:8(5):405-13.

32. Tait SW, Green DR. Mitochondrial regulation of cell death. Cold Spring Harbor Perspect Biol. 2013. https://doi.org/10.1101/cshperspect.a008706.
33. Madungwe NB, Feng Y, Lie M, Tombo N, Liu L, Kaya F, Bopassa JC. Mitochondrial inner membrane protein (mitofilin) knockdown induces cell death by apoptosis via an AIF-PARP-dependent mechanism and cel cycle arrest. Am J Physiol Cell Physiol. 2018;315(1):C28-c43.

34. Pasparakis M, Vandenabeele P. Necroptosis and its role in inflammation. Nature. 2015;517(7534):311-20.

35. Krysko O, Aaes TL, Kagan VE, D'Herde K, Bachert C, Leybaert L, Vandenabeele P, Krysko DV. Necroptotic cell death in anti-cancer therapy. Immunol Rev. 2017;280(1):207-19.

36. Han W, Li L, Qiu S, Lu Q, Pan Q, Gu Y, Luo J, Hu X. Shikonin circumvents cancer drug resistance by induction of a necroptotic death. Mol Cancer Ther. 2007;6(5):1641-9.

37. Duffy MJ, McGowan PM, Gallagher WM. Cancer invasion and metastasis: changing views. J Pathol. 2008;214(3):283-93.

38. Chen VW, Ruiz BA, Hsieh MC, Wu XC, Ries LA, Lewis DR. Analysis of stage and clinical/prognostic factors for lung cancer from SEER registries: AJCC staging and collaborative stage data collection system. Cancer. 2014;120(Suppl 23):3781-92.

39. Turpeenniemi-Hujanen T. Gelatinases (MMP-2 and -9) and their natural inhibitors as prognostic indicators in solid cancers. Biochimie. 2005;87(3-4):287-97

40. Muhammad T, Sakhawat A, Khan AA, Huang H, Khan HR, Huang YH, Wang J. Aloperine in combination with therapeutic adenoviral vector synergistically suppressed the growth of non-small cell lung cancer. J Cancer Res Clin. 2020;146(4):861-74.

41. Wyman B, Perl A. Metabolic pathways mediate pathogenesis and offer targets for treatment in rheumatic diseases. Curr Opin Rheumatol. 2020;32(2):184-91.

42. Xue M, Yao S, Hu M, Li W, Hao T, Zhou F, Zhu X, Lu H, Qin D, Yan Q, et al. HIV-1 Nef and KSHV oncogene K1 synergistically promote angiogenesis by inducing cellular miR-718 to regulate the PTEN/AKT/mTOR signaling pathway. Nucleic Acids Res. 2014;42(15):9862-79.

43. Lin Y, Deng W, Pang J, Kemper T, Hu J, Yin J, Zhang J, Lu M. The microRNA-99 family modulates hepatitis B virus replication by promoting IGF1R/PI3K/Akt/mTOR/ULK1 signaling-induced autophagy. Cell Microbiol. 2017. https://doi.org/10.1111/cmi.12709.

44. Xiong Y, Lan J, Huang K, Zhang Y, Zheng L, Wang Y, Ye Q. PP2AC upregulates PI3K-Akt signaling and induces hepatocyte apoptosis in liver donor after brain death. Apoptosis Int J Programm Cell Death. 2019;24(11-12):921-33

45. Umesalma S, Kaemmer CA, Kohlmeyer JL, Letney B, Schab AM, Reilly JA, Sheehy RM, Hagen J, Tiwari N, Zhan F, et al. RABL6A inhibits tumor-suppressive PP2A/AKT signaling to drive pancreatic neuroendocrine tumor growth. J Clin Investig. 2019;130:1641-53.

\section{Publisher's Note}

Springer Nature remains neutral with regard to jurisdictional claims in published maps and institutional affiliations.

Ready to submit your research? Choose BMC and benefit from

- fast, convenient online submission

- thorough peer review by experienced researchers in your field

- rapid publication on acceptance

- support for research data, including large and complex data types

- gold Open Access which fosters wider collaboration and increased citations

- maximum visibility for your research: over 100M website views per year

At BMC, research is always in progress.

Learn more biomedcentral.com/submissions 